\title{
Stereotypes and the Shaping of Identity
}

\author{
K. Anthony Appiah $\dagger$
}

I have spent a good deal of time over the years thinking about how our racial identities should figure in our moral and political livesreflecting, that is, on the ethical significance of one dimension of difference. ${ }^{1}$ I have thought about these questions as a moral philosopher and not as a legal theorist, and so I have not had to work within the constraints imposed by the law and the history of its interpretation. The advantage of this freedom is that one may reflect on how things should be, unconstrained by the necessity of deference to the confusions of the executive, legislative, and judicial branches of our government. The disadvantage is that one can find oneself proposing norms or practices that have no chance at all of being implemented, and giving advice that seems, in the justly derogatory sense, "merely theoretical." So it is cheering to find someone like Professor Post, who both recognizes an important moral truth about the ethical significance of difference and believes that it can be brought to bear in the practical business of interpreting actually existing American antidiscrimination law.

The moral truth I have in mind is the importance of a distinction that is at the heart of Professor Post's characteristically elegant Lecture, that between treating people equally, on the one hand, and treating them as if they were the same on the other-the distinction, as one might put it, between equality and sameness. The Vonnegut story he quotes rightly represents as wildly dystopian a world in which everyone is pushed towards sameness. ${ }^{2}$ This story should make us suspicious of that interpretation of equality as an ideal.

Copyright $\odot 2000$ Califomia Law Review, Inc.

$\div$ Professor of Afro-American Studies and Philosophy, Harvard University. I would like to thank the editors of the Califonia Law Review for their many helpful suggestions. I would also like to thank the students of two New York University Law School classes, one on identity and the other on race and racism, which I taught while I was writing this paper. Their thoughts have had a pervasive effect on my thinking about these matters.

1. See, e.g., K. Anthony Appiah, In My Father's House: Africa in the Philosophy of Culture (1992); K. Anthony Appiah \& Amy Gutmann, Color Conscious: The Political MORALITY OF RACE (1996).

2. See Robert Post, Prejudicial Appearances: The Logic of American Antidiscrimination Law, 88 Calif. L. Rev. I, 4 (2000). 
Professor Post does a thoroughly convincing job of showing how unhelpful the picture of equality as sameness has been. He urges on us an approach in which, rather than pretending that difference does not exist, we take on, in part through legal action, the social reshaping of identities. The cases he explores center on gender, though he makes important observations along the way about race; but the conclusion he wants to draw applies to both of them, and to other forms of identity, such as sexual orientation and disability as well. He wants us to think of the project of antidiscrimination in all of these cases as one of re-shaping identities rather than ignoring them. But he does not say very much-and he says nothing directly and explicitly - about what norms should guide this reshaping. ${ }^{3}$ So I shall try, in the next Part, to sketch in some features of a more direct and explicit account. I do not propose a general account of the ways in which it is appropriate to seek to reshape identities. ${ }^{4}$ But I want to say enough to connect the question of antidiscrimination with some central liberal ideas-in particular, in Part II, with autonomy, dignity, and individuality. Against this background, in Part III, I will then take up the issue of "stereotypes." Here I shall be more explicitly critical than Professor Post is of current judicial façons de parler: for I think the way this word is used conflates a number of distinct issues. ${ }^{5}$ In Part IV, I make some concluding observations about why affirmative action, in the form of racial or gender preferences, need not be inconsistent with antidiscrimination properly construed-that is, as Professor Post and (as he points out) Justice Brennan in Weber ${ }^{6}$ both construe it.

The best way, I think, to grasp the power of the idea of equality is to think about the past practices against which those who have espoused the ideal were reacting. Slavery, Jim Crow, and what John Stuart Mill called the "Subjection of Women"; the denial of civic rights to ethnic and religious minorities and to homosexuals; systems of caste and class: All these have evoked an ideal of equality in counterreaction to them. This suggests to me that it is not disparate treatment as such-not merely treating a meinber of class $A$ differently from a member of class $B$-but rather some fairly specific kinds of disparate treatunent that people have had in mind.

3. In fact, he says that he will "not attempt to argue for any particular set of principles that ought to guide the application of antidiscrimination law." See id. at 32.

4. Amy Gutmann and I have discussed some of the issues at stake elsewhere. See ApPIAH \& GUTMANN, supra note 1 .

5. I do not think Professor Post makes these conflations, but I think he could have done more to draw attention to the muddles to which I try to draw attention.

6. United Steelworkers of America v. Weber, 443 U.S. 193 (1979).

7. See John Stuart Mill, The Subjection of Women (Susan Moller Okin ed., Hackett Pub. Co. 1988) (1869). 
After all, nobody thinks it offends equality to send some people to jail and not others-even though such treatment on the part of the state could hardly be more disparate-because there is an important difference in a just legal system between the sheep and the goats-namely, that the goats have been found guilty of a crime. The reason this does not offend equality, of course, is that there is an ethically relevant distinction between the As and the Bs here. And I have always drawn the inference from such cases that the key to equality is best understood negatively: Equality as a social ideal is a matter of not taking irrelevant distinctions into account. All the work here will go into deciding what distinctions are relevant. But in my judgment that is exactly where the work should go.

To understand equality this way is to see it as requiring that we treat like cases alike, and thus to consider what makes two people or two kinds of people morally alike for current purposes. People should be treated differently because there are grounds for treating them differently (or at least no grounds for not doing so): Egalitarians are people who have strong views about which grounds are permissible (and impermissible). You might think that social identities-race, ethnicity, gender, class, sexuality, religious affiliation-are never proper grounds for disparate treatment; you might think, like some of the good burghers of Santa Cruz, that (at least when we are acting as employers and public officials) we ought not to treat the fat differently from the skinny, or the pretty from the plain. I used to think something Iike this myself, so I would not regard you as foolish if you did. But I no longer think that so general a proscription can be right.

And that is because of another important feature of equality as a social ideal; namely, that questions of equality largely arise when the treatment is not only disparate but in some way invidiously so. It is one thing to give pink cookies to the girls and blue ones to the boys, but another to give the boys expensive toys and the girls cheap trinkets. There are those who think we should never treat females and males differently as such-that is, that our ground for treating them differently should never be that they are men and women. I confess to thinking that such gender-blindness would be slightly crazy or, in our world at least, simply impossible. ${ }^{8}$ Sexuality, as it is currently configured, makes the distinction between males and females relevant for most people: Is it really wrong to pay more attention to the men than the women at the party, if I am on the lookout for a partner? Gender (and it is gender, not just sex) seems relevant-or at least seems so for most people. As I scan the party, what I am considering offering to a

8. Professor Post shares my skepticism about ignoring gender, of course. For example, he says that people are not "context-free" in ordinary social life, Post, supra note 2, at 15, and he later observes that "sexual attraction is so firmly attached to existing gender roles that the effort to transform [them] ... seems an implausible ambition for the law." Id. at 23. ("Implausible" is, 1 think, an understatement.) 
potential partner is not something that is invidious to offer only to someone who, for some reason and in some way, attracts me. 'There are perfectly possible criticisms of the structure of sexual desire: It seems wrong, for example, to be out looking for someone whom I will enjoy abusing, even if that is what turns me on. But I do not think it can be wrong to be out looking for a man, or for a woman, as such. (This, by the way, immediately makes gender and race different for the purposes of thinking about disparate treatment, since there seems to be no morally acceptable feature of human life that stands to racial identity as sexuality stands to gender. That is one of the reasons why, as Professor Post rightly observes, "antidiscrimination law seeks to exercise a far more sweeping transformation of race than of gender.") ${ }^{10}$

I am using "invidious" here as a term of art, to describe treatment that differentially affects $A$ and $B$ with the aim or effect of producing a result that disadvantages one or the other of them in virtue of her identity. So it is not enough that the outcome be disparate and to the disadvantage of one of them: It must be disparate because, in some sense, their identities are different.

\section{II}

Whether or not I am right about either of my points-that equality is not identity and that the ideal of equality is aimed at invidiously disparate treatment-Professor Post, in his sociological account of American antidiscrimination law, agrees with me. It used to be taken for granted that it was all right for the state and for private employers and those who provided public accommodations to make invidious distinctions between blacks and whites and between men and women. That is, it used to be thought to be all right to give as a reason for granting something to $A$ that you denied to $B$ - a job, access to a hotel, voting rights-that $A$ was white or male and $B$ was black or female. The statutes and the constitutional law making of the last thirty or more years include many attempts to move away from that practice and that assumption.

Professor Post's paper focuses on antidiscrimination as a principle in the laws regulating employment. But invidious disparate treatment occurs in many areas of social life, and it will be helpful, I think, to frame the issues he considers within a more general understanding. So let me define a category of what I shall call public actions. This is intended to cover actions taken by state officials in their official capacity-which are clearly subject to norms of nondiscrimination-but also to include actions undertaken by people in the course of hiring and managing employees and in

9. This is why Desperate, who writes to Miss Lonelyhearts, does not have a moral argument against those who fail to be sexually attracted to her. See id. at 6 .

10. Id. at 37. 
admitting people to and ministering to them in public accommodations. It is an interesting question why, in a liberal society, antidiscrimination should be enforced as a legal norm in the sphere of public actions that are not state actions. I think the answer is clear enough: In our world, allowing each of us a fair chance at developing a dignified, autonomous existence, in which we can pursue a life governed by aims and an identity that we have reflectively appropriated, requires that we have access to employment and public space, as well as to the rights and privileges of the citizen. Dignity and autonomy being the core liberal values, a liberal will want the state to insist on reasonable access to employment and to public space for all. Why limit this insistence to public actions? Because to include other spheres of action within the ambit of antidiscrimination law-to require me not to distinguish between men and women, blacks and whites, in my everyday interactions-would infringe on my capacity to construct my own life. Freedom of expression and of association are central to such selfconstruction, and requiring me to have dinner parties in which gender or racial identity does not feature as a ground for choosing the guests interferes with these freedoms.

Since liberals believe not just in dignity but in equal dignity, what is made available by the state should be made available equally to everyone. The invocation of equality here must mean that the rights in question should not be denied to anyone by virtue of a feature that is morally irrelevant in the context. And so here, in the crafting of these regulations, there is space for discussion of which features should and should not be taken into account.

Professor Post takes up exactly such a discussion when he distinguishes Fesel ${ }^{11}$ and Wilson, ${ }^{12}$ suggesting that gender is relevant in the context of sexual privacy but not in the context of the forms of service properly provided by airline staff. ${ }^{13}$ As he argues, this is the right way to make the distinction. But in comparing Fesel with Griffin, ${ }^{14}$ what matters is the relative weight of the sexual privacy rights of male prisoners and the rights of elderly women to equal treatment as prison guards. ${ }^{15}$ Here, then, it is not that prisoners have no sexual privacy rights (it would be wrong to broadcast photographs of showering prisoners for the gratification of the general public), but that these rights weigh less than the need to open to women-on the same terms as men-forms of employment previously closed to them.

\footnotetext{
11. Fesel v. Masonic Home of Delaware, Inc., 447 F. Supp. 1346 (D. Del. 1978).

12. Wilson v. Southwest Airlines Co., 517 F. Supp. 292 (N.D. Tex. 1981).

13. See Post, supra note 2, at 25-26.

14. Griffin v. Michigan Dep't of Corrections, 654 F. Supp. 690 (E.D. Mich. 1982).

15. See Post, supra note 2, at 27.
} 
I shall call the rights granted to us by laws that regulate public actions "public rights," and those that limit only actions taken by the state I shall refer to, in the usual way, as civil rights. Constraining employers, hotelkeepers, and the like by granting us public rights against them does indeed limit their freedom, but it does so in a way that is usually less central to their life projects than the opportunities they would deny us are to ours. (That is why the limitation to public actions is appropriate, though there is reasonable room for debate about exactly what belongs in the category of public action.) Where constraining an employer to grant us public rights does interfere profoundly with individual or collective projects-as requiring the Catholic Church to employ women as priests undoubtedly would-we cannot justify it on these grounds. And, since we must, as a result, adjudicate the claims of individuals against such organizations, we are speaking here of the balancing of opposing interests.

It would be a mistake to allow the centrality of a project to my individuality by itself to trump your interests in such cases: Do we want the centrality of anti-Semitic hatred to my life to entitle me to keep Jews out of my hotel, for example? And so, we are obliged also, in the end, to address the merits of the projects.

In attempting to avoid invidious discrimination in public actions on the grounds of gender or race, we discover at once that it is not enough simply to require that race and gender not figure in the announced reasoning of public actors. People and legislators can easily cover gender bias by pretending that it is really something else-long hair, earrings, the risk of motherhood - that they are worried about. That intentions are easy to disguise means that we have a reason to look beyond facial neutrality and see whether there is not an invidious hidden agenda. But there is a deeper reason than this why we must look beyond facial neutrality. The fundamental rationale that I sketched for public rights was that they provide opportunities for their beneficiaries that are essential to a dignified autonomous life: If an action deprives me of such an opportunity, it hardly matters, from this point of view, that this was not the result of intentional malice. Of course, it may be that the deprivation was by virtue of a morally relevant feature. (For example, I might have been deprived of my liberty because I committed a crime). Thus, it is important in assessing the harm done to me by the deprivation of an opportunity that we ask whether it can be justified. But if it cannot, then, so it seems to me, the fact that the agents of my deprivation did not intend to harm me seems less important than that they did in fact harm me. I may be entitled to a remedy, even if they are not reasonably to be subjected to punishment.

That, in my view, is why antidiscrimination law naturally leads to discussion of "disparate impact." It is also why something like a "bona fide occupational qualification" (BFOQ) exception seems natural as well: If 
my gender or nationality or racial identity are in fact relevant for the purposes of a public action, then there is nothing morally troublesome about taking them into account. (So we ought to admit the possibility of a BFOQ in the case of race, as the federal law does not, because there seems nothing harmful, in a realist production, in requiring that we have actors who look-and sound-like people of whatever racial identity they are representing.)

III

I have been doing what philosophers often do, namely, developing a general picture of the normative constraints on a social practice-in this case the legal granting of public rights against discrimination on grounds of gender and race-without taking much notice of actually existing practice. But I need this much by way of background in order to raise the two lines of discussion that I would like to raise about the clains Professor Post makes in his Lecture. Both of the lines I want to pursue are, I hope, in the spirit of friendly amendments; but the only way I know to think through what I believe about such things is from the sort of first principles I have been sketching.

The first line of discussion has to do with the promiscuous use of the word "stereotype" in the judgments that Professor Post quotes and discusses. In my view, this word is being asked to do too much work, and that has led to confusion. On the basis of the examples that Professor Post cites, it seems to me that "stereotype" in American antidiscrimination law covers at least three distinct ideas.

The first is the idea of ascribing to an individual a property in the belief that it is characteristic of some social group to which she belongs, where there is indeed a statistical correlation between that property and being a member of that group, but where, in fact, she does not have that property. This is the case of the strong woman, "Mary," who presents herself for a job as a firefighter and is told that she will not be considered because "women are not strong enough to be firemen." Here, there is a general fact about the group that is relevant to the employment decision: Strength, let us suppose, really is a bona fide occupational qualification for a firefighter, and women really are, on average, weaker than men. But this general fact does not bear on the question of Mary's suitability for the job if she is in fact stronger than most men-stronger, in fact, than the weakest male fireman. Let's call these statistical stereotypes.

Public action towards an individual based on a statistical stereotype when she is, in fact, atypical of her group, burdens her for no good reason. The economically minded will object that, given the statistical fact, there may be higher search costs in filling positions if you have to consider even members of groups who are characteristically not suitable for them than 
there would be if you were allowed to rule them out in advance. If the costs were astronomically higher or if they somehow burdened some employers more than others-for example, if much of their competition was from companies working in regimes without antidiscrimination law-then there might, indeed, be a cause for subsidy here. But there seems no good reason why the costs to the business should trump the costs to the qualified but unrepresentative member of her group. Rights, whether public in general or civil in particular, always have costs, and they are not always borne by the state. It strikes me as a fortiori true that the cost to business should not trump the cost to the potential employee if the fact that there are few qualified members of the group is the result of historical injustice or present discrimination. Professor Post isolates this issue in his discussion of the "paradigmatic example" of a "refusal to grant a BFOQ exemption to an employer who claims that women should not be hired for particular positions because 'the arduous nature of the work-related activity renders women physically unsuited for the jobs." "16 But, as I suggested at the start, I think it would be heIpful to point out how different statistical stereotypes and the issues they raise are from some other uses of the term "stereotype" in the case law, two of which I discuss immediately below.

A second idea invoked by the word "stereotype" is just a false belief about a group. In the context of antidiscrimination, the relevance of such stereotypes-let's call them simply false stereotypes-is that a public actor may give as her ground for doing something the belief that $A$ has some characteristic, because she believes that all members of a group to which $A$ belongs, have, or are very likely to have, that characteristic. And she may do this even when the characteristic is not, in fact, common in the group. The classic examples here are ethnic stereotypes, which lead people, say, not to do business with members of a group because they are purportedly shifty and dishonest, when, im fact, they are not, or at any rate not more so than anybody else. Simply false stereotypes burden people for no good reason, too. But to identify the burden may require an inquiry into the question whether the stereotype is in fact simply false.

The third, and, in my view, most interesting sense of the word "stereotype" comes up in the case of gender in relation to the discussion of norms of dress and behavior. Here a stereotype is not a view about how members of the group behave simpliciter. It is grounded in a social consensus about how they ought to behave in order to conform appropriately to the norms associated with membership in their group. I shall call this a normative stereotype. When employers require female employees to wear dresses and male employees not to do so, they are invoking normative gender stereotypes.

16. Id. at 19. 
It is perhaps worth observing that there are obvious connections between statistical and normative stereotypes. Many of the generalizations involved in statistical stereotyping are true because there are normative stereotypes to which people are conforming.

Now granting these distinctions, we can see that different kinds of stereotypes deserve different responses. Both the first and the second kinds of stereotypes involve intellectual error-either misunderstanding the facts, in the case of simply false stereotypes, or misunderstanding their relevance, in the case of statistical ones. But there is no reason to suppose that normative stereotypes as such must be wrong, or that public actions grounded on them are to be criticized, even where they involve differences in treatment that are judged to be invidious. For example, given the way the clothing market works, the demand made of a woman that she wear business attire appropriate to her sex may well require her to spend more money than the same demand made of her male colleagues. That makes it invidious, in my term-of-art sense, since she is paying a cost by virtue of her gender. But it is at least not obvious to me that this is a harm that rises to the level of requiring a public right, or the expenditure of public funds, to remedy it.

We can now revisit a few of the cases Professor Post discusses with these distinctions in mind. Begin with the Santa Cruz ordinance. Those who favored it, Professor Post says, did so because they thought that employment and housing decisions ought not to depend on an "irrelevant characteristic" and that "decisions based upon appearance so often merely express "simple bigotry." .17 A characteristic is irrelevant to whether or not someone will be a good employee if it gives no indication of his capacity to do the job, and it is irrelevant to whether or not he will be a good tenant if it gives no indication as to whether he will be clean and quiet, and pay his rent on time. Here the defenders were arguing that appearance invoked simply false stereotypes. They might also have argued that statistical stereotyping was a danger and that the ordinance would encourage employers and landlords to take special care to examine whether people whose appearances they disliked would actually be good employees or tenants. The suggestion that trying to "control the look of their workforce"18 echoed the mentality that led to anti-black discrimination in housing and employment suggests, however, that they might also have had normative stereotypes in mind. In particular, in relation to dress and self-chosen aspects of appearance, it might be that what they were objecting to was the attempt to enforce norms in areas that properly should be under the control of the individual. These strike me as arguments worth considering-and as

17. Id. at 3.

18. Id. (quoting Stephen G. Hirsch, Santa Cruz Law Could Be Attacked For Vagueness; Proposed Ordinance Would Bar Bias Based on Appearance, THE RECORDER, Jan. 17, 1992, at 1). 
better arguments than those suggested by the idea that equality requires either sameness or blindness to difference.

But I think the heart of their argument had very little to do with stereotyping, even though it seems to have been invoked a good deal in the discussion. For the real argument about discrimination in the area of appearance was that what employers and landlords were doing was expressing their distaste for or discomfort with people whom they found in various ways unattractive: obese people, people with an eccentric sense of dress or bodily adornment, and the like. ${ }^{19}$ What is wrong with this is that it places a burden on people either in respect of a characteristic over which they have no control (ugliness, say) or over which they are entitled to maintain control themselves; for those characteristics that I ought to be entitled to regulate myself, the threat of being fired or being unable to find a place to live is illegitimately coercive. ${ }^{20}$ The problem is not stereotyping but bigotry-i.e., unjustified hatred or contempt. (I do not deny that there are connections between stereotyping and bigotry: Bigotry often leads to stereotyping and stereotyping can lead to bigotry. But each can stand alone.)

In the passages of judicial interpretation of Title VII that Professor Post cites towards the beginning of his discussion of the Federal Civil Rights Act of 1964, there is some mention of stereotypes, but the primary focus is not on normative stereotypes. ${ }^{21}$ The Court speaks of "stubborn but irrational prejudice" in Lam $v$. University of Hawaii, ${ }^{22}$ suggesting that it is cognitive problems-simply false or statistical stereotyping-that are at issue. In Donohue v. Shoe Corp. of America ${ }^{23}$ there is explicit mention of forming "opinions of people on the basis of skin color, religion, national origin, ... and other superficial features." Similarly, in the ensuing discussion of state antidiscrimination statutes, there is talk of "stereotyped impressions about the characteristics of a class to which the person belongs," which could also mean either that the characteristics are

19. See id. at 5-6.

20. 1 am here taking up Professor Post's suggestion, in his discussion of the Santa Cruz ordinance, that discrimination on the basis of appearance threatens autonomy. See id. at 5-6. But I do not accept the idea that Professor Post suspects may underlie "legal judgments of unfaimess," namely that it depends on "whether a stigmatizing attribute is ... somehow essential or integral to a person, as is their religion." Id. at 9. For the range of considerations that it seems proper to exclude in distinguishing people in a certain context may include characteristics that are mutable and important (like religion), mutable and unimportant (like hair color), immutable and unimportant (like eye-colorat least for the moment), immutable and imporant (like race-as normally understood). Most people I know would find it unfair to deny a job to someone because their eyes were blue, their hair was dyed red, or they were Catholic or Asian, at least in the absence of some connection between these properties and the nature of the task. (Professor Post does not, of course, endorse the view he here ascribes to the legal mind: It is possible that he, too, shares my sense that it is mistaken.)

21. See id. at 10.

22. 40 F.3d 1551, 1563 (9th Cir. 1994).

23. 337 F. Supp. 1357,1359 (C.D. Cal. 1972). 
incorrectly assigned to the class (simply false stereotyping) or to the individual (statistical stereotyping). ${ }^{24}$

But there are hints all along that normative stereotyping is also in the offing. When Justice Brennan in Price Waterhouse v. Hopkins ${ }^{25}$ interprets federal law as insisting that "sex, race, religion and national origin are not relevant to the selection, evaluation, or compensation of employees," he must mean that they are not relevant in se, since they are clearly relevant statistically. To say that they are irrelevant in se might seem to be to reject normative stereotypes that declare certain jobs suitable or unsuitable for African Americans or for women. Someone who neither invalidly invokes statistical stereotyping to mis-assess an individual nor wrongly characterizes the abilities of women or African Americans inight nonetheless believe that each has a proper place that is different from the place of men or of white people.

Thus, I am not inclined to accept Professor Post's account of stereotypes as "the conventions that underwrite the social practices of gender." 26 For that suggests that stereotypes are reducible to normative stereotypes. Nevertheless, this is, in essence, something of a semantic disagreement, since he does in fact distinguish between stereotypes in his sense and questions concerning the relevance of statistical generalizations about classes of people to the treatment of individuals in those classes.

The importance of normative stereotypes-which I have elsewhere called scripts for identities ${ }^{27}$-is central to understanding the place of identity in moral and civic life. I do not have time now to explore the question why it is that social identities are so crucial for our individualities. But if, as liberals at least since John Stuart Mill have proposed, the construction of one's own individuality, the creation of a self, is indeed a project for every human life, and if, as much recent multicultural and feminist discussion has made plain, collective identities are a resource for that self-creation and not just a hindrance, then it follows that we must accept the existence of normative stereotypes. For a social identity is, among other things, a set of normative scripts for shaping your behavior, your plans, your life. If this is right, however, not just any normative stereotypes will do. They have to be configured in such a way as to serve as potential instruments in the construction of a dignified individuality. To the extent that existing norms, enforced through public action, construct an identity as lacking in dignity, or have built into them the inferiorization of those who bear it, they are not

24. Post, supra note 2, at 10-11 (citing Miller v. C.A. Muer Corp., 420 Mich. 355, 362-63 (1984)).

25. 490 U.S. 228,239 (1989) (Brennan, J., plurality opinion).

26. Post, supra note 2, at 18.

27. See K. Anthony Appiah, Identity, Authenticity, Survival: Multicultural Societies and Social Reproduction, in Multiculturalism: Examining "The Politics of Recognition" 149-63 (Amy Gutmann ed., 1994). 
such instruments. I think Professor Post is entirely right, then, to insist that what matters in antidiscrimination law is the reshaping of gender norms, not their abolition. The abolition of gender norms, as I say, would be the abolition of gender and the radical reformulation-perhaps beyond human recognition - of sexuality. But their reform could begin to make it less true that our society constructs women as inferior to men.

It is an interesting question what we should say about racial identities here. If identifying as an African American (the socially constructed identity, not some putative biological race) is a source of value in the shaping of the modern identities of at least some Americans of African ancestry, then it seems to me that we must accept that at least some normative stereotypes-about dress or speech or participation in Kwanza, for example-have value. But it would still be open to us to say that, while such normative stereotypes do indeed have value, their value does not make them a suitable basis for invidiously different treatment in the sphere of what I have called public actions. I doubt myself that this is right, at least at the moment. For to say that would be to require that there be no public acts that disadvantaged members of any racial group. And, as Post rightly points out, ${ }^{28}$ that would rule out any form of affirmative action in relation to race.

This last claim is controversial because some deny that affirmative action for racial minorities disadvantages white people by virtue of their race. It is a coherent position that advantaging a Latina in a competition for a job or a place at a university does not deprive any white person of anything, since the job or the place was not something to which he was entitled. However, I prefer to accept that in affirmative action there are winners and losers, but that there is sometimes a justification for the practice nevertheless.

Professor Post rightly remarks that the "law seeks ... a far more sweeping transformation of race than of gender." ${ }^{29}$ I think that the exploration of the ways in which collective identities serve to shape lives positively as well as negatively might lead the law-or, at any rate, some of its practitioners-to be more tolerant of the idea that racial identities can be a proper basis for distinguishing between people.

\section{IV}

The final line of thought I want to take up briefly is also relevant to thinking about affirmative action. Once we accept Professor Post's picture of American antidiscrimination law, judges and legislatures and citizens must take up the question of which forms of invidiously disparate public action require remedy. We cannot prudently attempt to deal with all of

28. See Post, supra note 2, at 38.

29. Id. at 37 . 
them, making it a crime, for example, to be less courteous to black than to white guests at hotels. (If my experience in this country is anything to go by, this would be one of the easiest ways of increasing the white prison population.) I think there is an obvious way to focus such discussions. It is to ask how central that form of public action is to maintaining sexual or racial inequality. Since racism and sexism are systematic and patterned, not mere accidental agglomerations of individualized prejudices, this is a reasonable question. And I think that those judges who have found it unreasonable to require employers to allow men to wear their hair long, ${ }^{30}$ for example, could rightly have given as their rationale the fact that such employer's preferences simply play too small a role in shaping gender in ways that disadvantage women. Similarly, requiring Morehouse to admit more white students strikes me as something that will not reduce racial inequality in America, while integrating the elite schools that had historically excluded black people certainly was an important step in that direction. I think this proposal also allows us to make a plausible distinction between Wilson (the case involving Southwest Airlines flight attendants) ${ }^{31}$ and Craft (the case of the female TV news anchor) ${ }^{32}$ Here we can say that the practice of offering airline service that is aimed at attracting heterose $x$ ual men of conventional tastes by requiring women to "act sexy" for them is demeaning to women, and sustains male supremacy, in a way or to a degree that requiring a woman news anchor to "maintain professional, businesslike appearances, 'consistent with community standards," does not. ${ }^{33}$ In fact the standards invoked by the television station in Craft presuppose that women, though governed by different norms of dress, are nevertheless properly to be found in professional, business positions. I do not deny that the codes of dress for women in the "conservative" Kansas City market ${ }^{34}$ are likely to play a role in limiting the opportunities of businesswomen or reflect a lack of equal respect for them. But they do so, I believe, to a significantly lesser degree than do the codes requiring airline attendants to engage in "sexy dressing."

My proposal is, of course, a proposal about one of the issues that should be taken up by courts in deciding how to re-shape gender and race in America: It is a proposal that could be taken up only by a court that had already grasped the sociological account of antidiscrimination law articulated by Professor Post. So I would hope that the elegance of his arguments will persuade not just me but some of those public actors who have to construct and administer American antidiscrimination law.

\footnotetext{
30. See id. at 28 n.135.

31. Wilson v. Southwest Airlines Co., 517 F. Supp. 292 (N.D. Tex. 1981).

32. Craft v. Metromedia, lnc., 766 F.2d 1205 (8th Cir. 1985).

33. Post, supra note 2, at 24 (quoting Craft, 766 F. 2d at 1209-10).

34. See id.
} 
